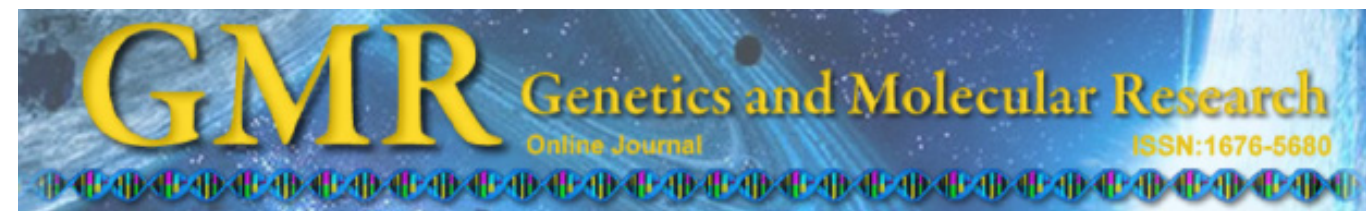

\title{
Genetic assessment of the Atlantic Forest bristle porcupine, Chaetomys subspinosus (Rodentia: Erethizontidae), an endemic species threatened with extinction
}

\author{
C.G. Oliveira ${ }^{1}$, R.A. Martinez ${ }^{2}$, G.A.F. Giné ${ }^{1}$, D.M. Faria ${ }^{1}$ and \\ F.A. Gaiotto ${ }^{1}$ \\ ${ }^{1}$ Departamento de Ciências Biológicas, Universidade Estadual de Santa Cruz, \\ Ilhéus, BA, Brasil \\ ${ }^{2}$ Departamento de Filosofia e Ciências Humanas, \\ Universidade Estadual de Santa Cruz, Ilhéus, BA, Brasil \\ Corresponding author: F.A. Gaiotto \\ E-mail: gaiotto@uesc.br / fagaiotto@gmail.com
}

Genet. Mol. Res. 10 (2): 923-931 (2011)

Received August 26, 2010

Accepted October 27, 2010

Published May 24, 2011

DOI 10.4238/vol10-2gmr1039

\begin{abstract}
The bristle-spined porcupine, Chaetomys subspinosus, an endemic rodent from Atlantic Forest, was considered to be abundant in the recent past, but population reductions due to habitat loss and expansion of human activities caused this species to be included in the "vulnerable" category of the World Conservation Union Red List. We performed the first genetic assessment in natural populations of this focal species along its geographical distribution. Thirty-five noninvasive samples (hair) were collected from three natural populations in the Brazilian States of Sergipe, Bahia and Espírito Santo. Genetic similarity obtained by Jaccard's index, based on dominant RAPD and ISSR markers, varied between 25 and $100 \%$. Four clusters, mainly coincident with the geographical distribution of the populations, were
\end{abstract}


observed. Analysis of molecular variance based on 47 polymorphic loci showed that there was $15.99 \%$ genetic variability among populations and $84.01 \%$ within populations. The estimated genetic structure among populations $\left(\phi_{\mathrm{ST}}\right)$ was 0.16 . The populations may have formed a continuum along the past distribution of the Atlantic rainforest but historical events of human occupation resulted in recent divergence among sampled populations.

Key words: AMOVA; Conservation; Endemism; Genetic diversity; Molecular markers

\section{INTRODUCTION}

The bristle-spined porcupine, Chaetomys subspinosus Olfers 1818 (Rodentia: Erethizontidae), is a medium-sized rodent endemic to the northeastern Atlantic Forest of Brazil. As a member of the Erethizontidae family (Chaetomyinae subfamily, $2 \mathrm{n}=52$ chromosomes) (Vilela et al., 2009), it has quills restricted to head, neck and forelimbs, and the rest of the body is covered by soft, brow spines resembling the bristles of a broom (Moojen, 1952; Nowak and Paradiso, 1983; Roze, 2009).

The species was once considered to be common locally, distributed along the eastern coast of the Atlantic Forest from Rio de Janeiro to Sergipe (Oliver and Santos, 1991). Its current habitat is restricted to patches of Atlantic Forest (Santos et al., 1987; Oliver and Santos, 1991). Following the drastic reduction of the Atlantic Forest to less than $7 \%$ of its original area, C. subspinosus populations are currently fragmented and probably in decline. Given this picture, the species is listed as vulnerable on the Red List of both the IUCN (Catzeflis et al., 2008) and the Brazilian government (MMA, 2011), suggesting that remnant populations require immediate conservation measures. Despite this situation, the elaboration of a specific conservation strategy for the focal species is limited due to lack of basic information regarding the species' biology. This is clearly illustrated by the fact that only two field studies have been conducted with this species, focusing on its distribution range (Santos et al., 1987) and some aspects of its natural history (Chiarello et al., 1997; Giné et al., 2010).

The degradation and loss of natural habitat associated with inbreeding depression, competition for food and water, and predation have been suggested as factors that could have contributed to the population decrease, in addition to disease transmission resulting in the constriction and reproductive isolation of wild populations of threatened and endangered species. A critical issue facing the conservation and management of species inhabiting fragmented forest is the potential for the reduction of genetic diversity, which often ensues from an increase in genetic drift as the effective population size decreases (Nei, 1987).

Conservation of many threatened species has highlighted the importance of genetic data, and the maintenance of genetic diversity is a major goal for various biodiversity conservation programs (Frankham et al., 2002). Population or species viability depends on stochastic and deterministic demographic, environmental and genetic events. Estimations of genetic diversity can be very important in programs for biodiversity conservation, but such data need to be used with caution (Faria and Miyaki, 2006). 
There are different molecular markers available to address genetic diversity within populations. RAPDs (random amplified polymorphic DNA), described by Williams et al. (1990), are small conserved sequences dispersed throughout the genome, guaranteeing ample genomic sampling of the individual without evidence of clustering in any specific region. This facilitates attainment of fragments located within repetitive sequences and coding regions (Williams et al., 1990). Hypervariable intersimple sequence repeats (ISSR) are based on primers of short repeated sequences annealing within microsatellite regions, amplifying non-repeated anonymous fragments (Gupta et al., 1994). They are also known as single primer amplification reactions and have been reported for plants and animals (Gupta et al., 1994; Fernandes-Matioli et al., 2000; Frankham et al., 2002).

In this study, we addressed genetic variability and the population genetic structure of C. subspinosus along its current geographical distribution. This is the first study to provide population genetics data of this threatened, Neotropical mammal. It is expected that this information, merged and analyzed with other sources of sound biological data, will support a National Management Plan to identify priority areas and measurements for the conservation of $C$. subspinosus.

\section{MATERIAL AND METHODS}

\section{Biological samples}

This study was part of a broader project aiming at a national conservation proposal for the species. It has been conducted in accordance with Brazilian laws of wildlife manipulation, and possesses all the necessary official permits for animal handling in the field as well as access to genetic information for Brazilian fauna. Animals were handled at all times in a humane manner, without compromising their lives and/or physical safety by sampling or radio-collaring. During the assessment of its current geographic distribution and auto-ecological studies, we performed surveys in forest remnants present in the northeastern States of Sergipe (SE), Bahia (BA) and Espírito Santo (ES), following its historical geographic range (Santos et al., 1987). Captures were made in low vegetation habitats and possible resting sites such as entangled lianas, typical formations known as "baceiros", tree trunks and bromeliads, as they form potential microhabitats for these individuals. After the localization of an animal the tree was climbed and the individual was removed from the vegetation and held by the neck with leather gloves to put on a radio collar for population studies. It is noteworthy that, although the present study relies on a sample of only 35 individuals, the actual sampling effort was extremely high and never achieved before. Due to its cryptic habits, the bristle-spined porcupine is very difficult to both detect in nature and also to capture. In the present study, only 11 animals were captured after $217 \mathrm{~h}$ of actively searching, while the remaining samples were obtained from animals captured and observed by locals during this study. Quills (and the thin hairs underneath) were then collected by plucking. Samples were wrapped in tinfoil and kept in a dark and dry environment until they were delivered to the laboratory, where DNA extraction took place. We obtained a total of 36 samples: five from the SE population, district of Santa Luzia do Itanhi (Sergipe), and Salvador, Ubaíra and Cachoeira (Bahia), 16 from the BA population (districts of Itacaré, Una, Uruçuca, Ilhéus,) and 15 from the ES population (district of Guarapari) (Figure 1). 


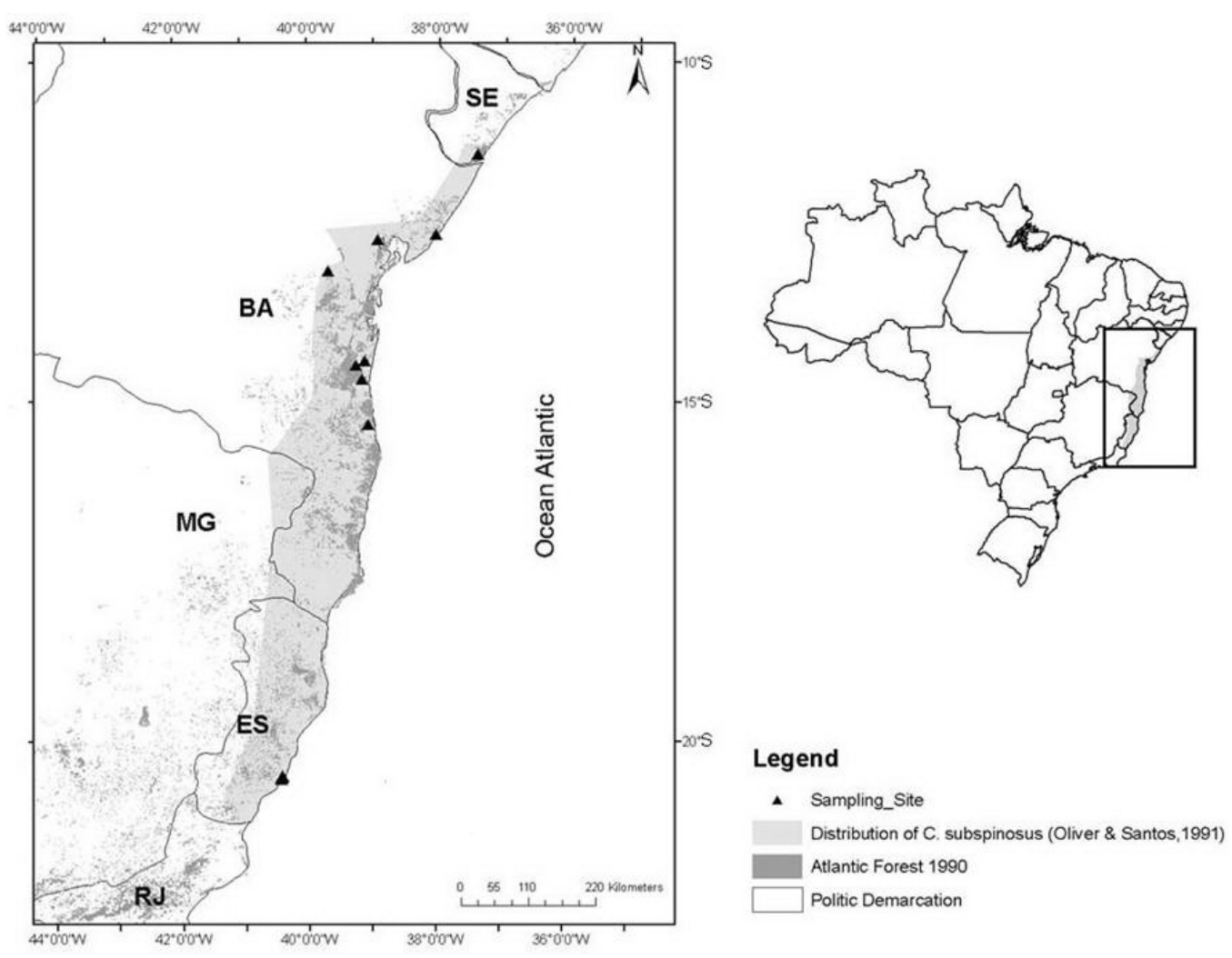

Figure 1. Location of sampling areas, labeled as a triangle symbol, within the range of Chaetomys subspinosus along the Atlantic Forest, Brazil.

\section{DNA extraction, RAPD and ISSR markers}

For DNA extraction most of the quill was discarded, leaving the bulb and around 2-3 $\mathrm{mm}$ of the remaining hair. An innovative protocol for non-destructive samples was standardized (Oliveira et al., 2007). DNA was compared with known standards of DNA $\lambda$ phage (Invitrogen) to certify quality of extraction and infer DNA quantity. Screening of 77 RAPD and 10 ISSR primers (Operon Technologies) was done according to Williams et al. (1990). Gels were photographed under UV light with a Kodak EDAS 24.0 photo documentation system.

\section{Genotyping and data analysis}

The individuals were genotyped by the presence (1) or absence (0) of bands in a binary data matrix. Genetic diversity between individuals was estimated using the Jaccard similarity index. UPGMA was used to group the Jaccard matrix data phenetically. The genetic similarity matrix and the dendrogram were calculated using NTSYS 1.70 (Rohlf, 1992).

Populational genetic diversity and structure was calculated using AMOVA, with both 
the AMOVA-PREP (Miller, 1998) and the Winamova software programs (Excoffier et al., 1992). The AMOVA was based on Euclidean squared genetic distances among individuals sampled using the methods described by Huff et al. (1993).

\section{RESULTS}

Of the 77 RAPD primers analyzed 23 were selected, and of the 10 ISSR primers tested two were selected that showed satisfactory results based on the number of clean, bright, and easily interpretable and reproducible polymorphic bands produced.

Average genetic Jaccard similarity based on ISSR and RAPD molecular markers, varied between 25 and $100 \%$. Four clusters, mainly coincident with the geographic distribution of the populations were observed (Figure 2).

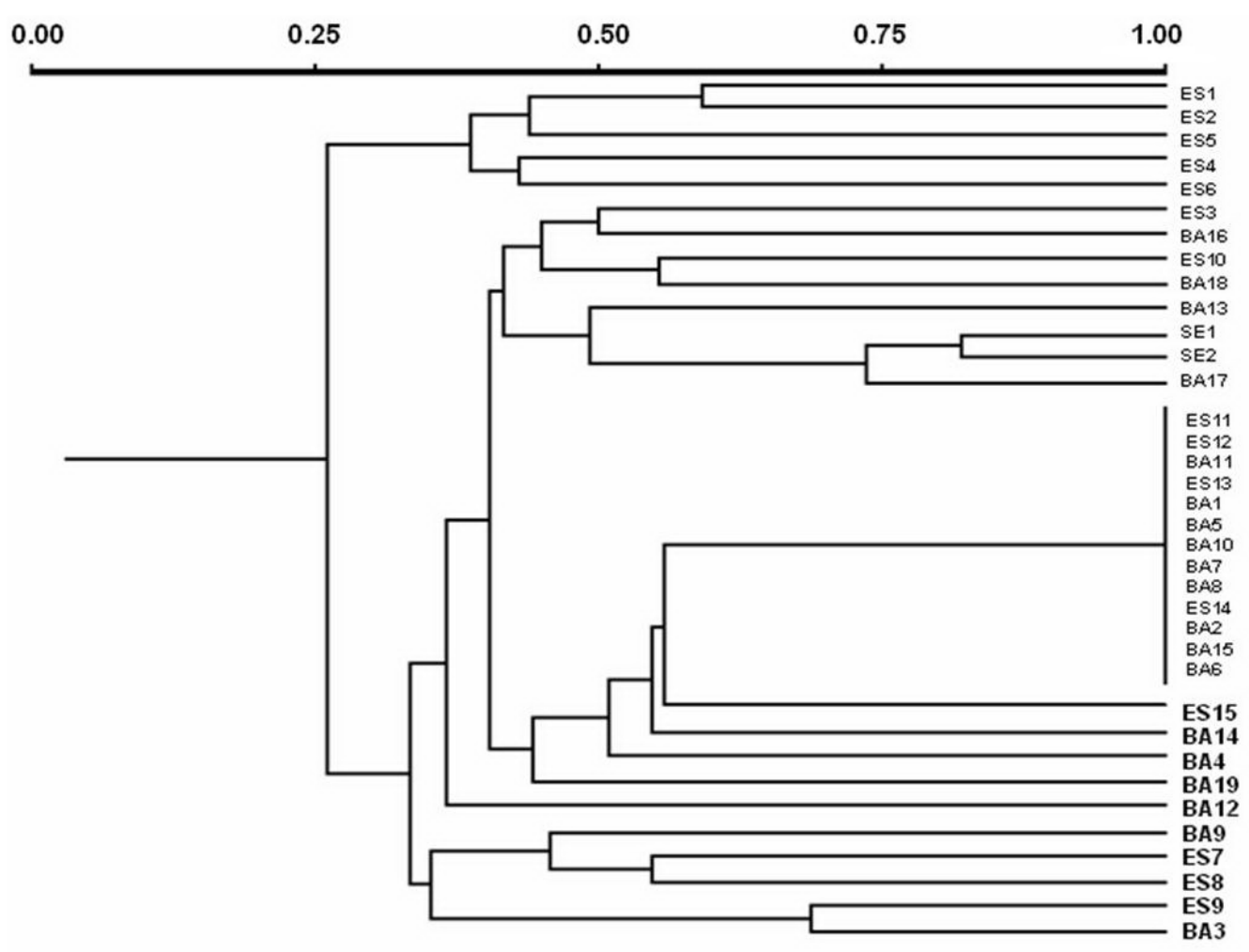

Figure 2. Jaccard genetic similarity dendrogram based on individual samples of Chaetomys subspinosus using UPGMA. BA, SE and ES represent individuals sampled in Bahia, Sergipe and Espírito Santo, respectively.

The first cluster had animals exclusively from Espírito Santo (ES1, ES2, ES4, ES5, ES6). The second was formed by individuals from Espírito Santo (ES3 and ES10), northern Bahia (BA13, BA16, BA17, and BA18) and Sergipe (SE1 and SE2). The third cluster was composed of nine individuals from southern Bahia (BA11, BA1, BA5, BA10, BA7, BA8, BA2, BA15, and BA6) and 4 from Espírito Santo (ES11, ES12, ES13, and ES14), showing 
$100 \%$ similarity considering all 47 markers. The fourth cluster presents $30 \%$ similarity among individuals from districts of Una and Ilhéus in southern Bahia and Espírito Santo (BA14, BA4, BA19, BA12, BA9, ES7, ES8, ES9, and BA3) (Figure 2).

The analysis of molecular variance based on 47 polymorphic loci showed that there was $15.99 \%$ genetic variability among populations and $84.01 \%$ within populations. The estimated $\phi_{\mathrm{ST}}$ was 0.16 (Table 1).

Table 1. Analysis of molecular variance (AMOVA) on Chaetomys subspinosus populations from Bahia, Sergipe
and Espírito Santo States, Brazil, based in dominant molecular markers.
\begin{tabular}{lccc}
\hline Source of variation & Total variation & $P$ & Statistics $\Phi_{\mathrm{ST}}$ \\
\hline Between populations & $15.99 \%$ & $<0.0001$ & 0.16 \\
Within populations & $84.01 \%$ & $<0.0001$ & $1-\Phi_{\mathrm{ST}}=0.84$ \\
\hline
\end{tabular}

\section{DISCUSSION}

This study revealed important findings regarding population structure and genetic diversity of the focal species. The analysis of 47 RAPD and ISSR markers showed that there is substantial genetic divergence among populations of $C$. subspinosus along its distribution range, indicating the presence of strong genetic structure. This is probably a result of biogeographical processes, enhanced by their recent isolation due to anthropogenic forest fragmentation. The synergetic effect of species habitat requirements, local fragmentation patterns, and strong human hunting pressure might be the major factor underlying the decrease in gene flow among $C$. subspinosus populations. The Bahia sample is characterized by an apparent loss of genetic diversity, considering that 9 individuals of 27 shared $100 \%$ genetic similarity. The aforementioned sample showed a strong divergence from the Espírito Santo population, despite the close geographical distance between the two states. The Sergipe samples were less divergent than the Bahia ones, presumably as a result of more recent isolation events. Limited genetic differentiation among these populations implies that, historically, they might have once belonged to a single ancestral population. The analysis highlights the importance of the Espírito Santo population as a reservoir of genetic variability for the species.

Similar results, indicating low genetic diversity, have also been reported for maned sloths (Bradypus torquatus), another arboreal mammal endemic to the Atlantic Forest. DNA fingerprinting was used to estimate genetic variability within and among populations from different localities in Bahia. Two populations of Bradypus variegatus, one from Bahia and one from São Paulo, were also included in the same study. Genetic similarity indexes for these species varied from $0.34 \pm 0.07$ to $0.87 \pm 0.04$, and the authors attributed these results to bottleneck and founder effects (Moraes et al., 2002).

We detected a drastic reduction in the gene pool of $C$. subspinosus populations as a whole, since our estimated value of $\phi_{\mathrm{ST}}$ (Table 1) was high when compared to reference $\mathrm{F}_{\mathrm{ST}}$ (Conner and Hartl, 2004).

It seems that genetic relatedness among those individuals, although high, follows the same separation observed between Bahia and Espírito Santo individuals. Prior to recent anthropogenic-induced habitat modifications, there was a clear distinction between the two geographic regions, which accounted for the populations' ancient isolation. Therefore, these 
two separate clusters are both prone to genetic loss due to recent anthropic effects. So, groups anciently isolated due to biogeographical events grew more susceptible towards genetic pauperization because of anthropogenic effects, leading the populations to zero genetic variability, as is the case for the southern Bahia sample (Figure 2).

Populations that once formed a continuum along Espírito Santo and southern Bahia were fragmented by historical anthropic events, such as forest depletion and modifications (through introduction of exotic arboreal species, for example), which were stronger in northeastern Bahia and Sergipe due to the fact that the former regions were the first territories occupied by Europeans in 1500, and intensively cultivated from the XVI century until the present. Espírito Santo had less than $30 \%$ of its territory occupied by agricultural areas until 1920, and the severe deforestation that took place between the 1950s and 1970s was a consequence of the logging industry (IPEMA, 2005).

\section{Conservation prospects}

We can propose two management units (MUs) (Moritz, 1994) for the sampled $C$. subspinosus populations, the Bahia-Sergipe group along with the southern Bahia cluster, both with dangerously low genetic variability, and the Espírito Santo population that may represent the only source for variability in the studied populations.

The Espírito Santo MU is in urgent need of protection measures to guarantee its longterm survival. Furthermore, this park lacks connectivity with the rest of the forest patches, as it is surrounded by pastures. Thus, we can predict that populations will require immigrants in the near future in order to avoid genetic erosion by stochastic events. Therefore, management actions to manipulate the dispersal rates among these small isolated populations should be considered. This could be achieved by either undertaking planned translocations or by establishing corridors linking remnant habitats in order to allow this connectivity (MMA, 2006).

However, data from southern Bahia suggest that certain structural features of the habitats used to link forest patches should be taken into account to effectively allow dispersion among patches. Although southern Bahia comprises the largest and most continuous areas of forest cover along the distribution range of $C$. subspinosus, populations along this proposed MU showed the most critical levels of genetic erosion in our study. This apparently paradoxical situation may be partially explained by the fact that most of the forest cover in southern Bahia comprises extensive areas of shaded cacao plantations. In these so-called "cabrucas", the native canopy forest is thinned whereas the cacao shrubs largely replace the original understory, not allowing enough connectivity among the patches (Faria et al., 2007).

Similar to the Espírito Santo MU, populations from southern Bahia are also distributed along isolated and small remnants, but its loss of genetic variability points to a more serious challenge regarding their long-term viability.

Management actions for this MU may have to include strategies to mitigate genetic loss by geographic isolation. In addition, the amount of remnants available for this species in the region is in dire need of expansion, as in some landscapes less than 5\% of the land cover actually comprises native forests (Faria et al., 2006).

The Sergipe-Bahia group evidences geographic closeness in the near past. Nowadays, the forest remnants in both regions are patchily distributed and strongly influenced by human activities. Therefore, drastic conservation measures, such as animal translocations, are needed 
to increase genetic variability and prevent further erosion. A successful translocation experiment that increased the effective population size of a threatened bird (NI Saddleback) has already been reported (Parker, 2008).

We wish to stress the potential of dominant markers (i.e., RAPDs and ISSRs) as conservation tools, especially for species with scanty information such as C. subspinosus. They are quick and cheap ways to assess information that can be combined with other sorts of ecological data to support management options for conservation.

Our results represent the first genetic analysis ever made for this species. Due to the small sample size, we recommend further genetic evaluations. However, the inclusion of genetic information within any research seeking conservation and management of this endemic and secretive arboreal porcupine is a must if we wish to guarantee its long-term survival in a fragmented and fragile landscape.

\section{ACKNOWLEDGMENTS}

We are grateful to Götz Schroth, Janisete G.S. Miller, and Marco A. Costa for reading the manuscript and for constructive comments on a previous draft. We also acknowledge the support given by the Brazilian Ministry of Environment (MMA) through an FNMA Competitive Grant (\#02000.002787/2003-21 to D.M. Faria), the FAPESB through the M.Sc. fellowship to C.G. Oliveira. D.M. Faria and F.A. Gaiotto received research productivity fellowships from CNPq.

\section{REFERENCES}

Catzeflis F, Patton J, Percequillo A, Bonvicino C, et al. (2008). Chaetomys subspinosus. IUCN Red List of Threatened Species. Version 2009. Available at [http://www.iucnredlist.org/apps/redlist/details/4366/0]. Accessed November 21, 2010.

Chiarello AG, Passamani M and Zortéa M (1997). Field observations on the thin-spined porcupine, Chaetomys subspinosus (Rodentia: Echimyidae). Mammalia 61: 29-36.

Conner JK and Hartl DL (2004). A Primer of Ecological Genetics. 1st edn. Sinauer Associates, Inc., Sunderland.

Excoffier L, Smouse PE and Quattro JM (1992). Analysis of molecular variance inferred from metric distances among DNA haplotypes: application to human mitochondrial DNA restriction data. Genetics 131: 479-491.

Faria D, Laps RR, Baumgarten J and Cetra M (2006). Bat and bird assemblages from forests and shade cacao plantations in two contrasting landscapes in the Atlantic Forest of southern Bahia, Brazil. Biodivers. Conserv. 15: 587-612.

Faria D, Paciencia MLB, Dixo M and Laps RR (2007). Ferns, frogs, lizards, birds and bats in forest fragments and shade cacao plantations of two contrasting landscapes in the Atlantic Forest, Brazil. Biodivers. Conserv. 16: 2335-2357.

Faria PJ and Miyaki CY (2006). Molecular markers for population genetic analyses in the family Psittacidae (Psittaciformes, Aves). Genet. Mol. Biol. 29: 231-240.

Fernandes-Matioli FMC, Matioli SR and Almeida-Toledo LF (2000). Species diversity and geographic distribution of Gymnotus (Pisces: Gymnotiformes) by nuclear (GGAC) microsatellite analysis. Genet. Mol. Biol. 23: 803-807.

Frankham R, Ballou JD and Briscoe DA (2002). Introduction to Conservation Genetics. Cambridge University Press, Cambridge.

Giné GAF, Duarte JMB and Faria D (2010). Feeding ecology of a selective folivore, the thin-spined porcupine (Chaetomys subspinosus) in the Atlantic Forest. J. Mammal. 91: 931-941.

Gupta M, Chyi YS, Romero-Severson J and Owen JL (1994). Amplification of DNA markers from evolutionarily diverse genomes using single primers of simple-sequence repeats. Theor. Appl. Genet. 89: 998-1006.

Huff DR, Peakall LR and Smouse PE (1993). RAPD variation within and among natural populations of outcrossing buffalograss (Buchloe dactyloides (Nutt.) Engelm.). Theor. Appl. Genet. 86: 927-934.

IPEMA (2005). Conservação da Mata Atlântica no Estado do Espírito Santo: Cobertura Florestal e Unidades de Conservação. IPEMA, Vitória. 
Miller MP (1998). AMOVA-PREP. Department of Biological Sciences, Flagstaff.

MMA (2006). O Corredor Central da Mata Atlântica: uma Nova Escala de Conservação da Biodiversidade. Conservação Internacional e Fundação SOS Mata Atlântica, Brasília.

MMA (2011). Lista Nacional das Espécies da Fauna Brasileira Ameaçadas de Extinção. Available at [http://homolog-w. mma.gov.br/index.php?ido=conteudo.monta\&idEstrutura=179\&idConteudo=8110\&idMenu=8617]. Accessed May 9, 2011.

Moojen J (1952). Os Roedores do Brasil. Instituto Nacional do Livro, Rio de Janeiro.

Moraes N, Morgante JS and Miyaki CY (2002). Genetic diversity in different populations of sloths assessed by DNA fingerprinting. Braz. J. Biol. 62: 503-508.

Moritz C (1994). Defining evolutionary significant units for conservation. Trends Ecol. Evol. 9: 373-375.

Nowak RM and Paradiso JL (1983). Walker's Mammals of the World. The Johns Hopkins University Press, Baltimore, London.

Nei M (1987). Molecular Evolutionary Genetics. Columbia University Press, New York.

Oliveira CG, Martinez RA and Gaiotto FA (2007). DNA extraction from bristles and quills of Chaetomys subspinosus (Rodentia: Erethizonthidae) using a novel protocol. Genet. Mol. Res. 6: 657-666.

Oliver WLR and Santos IB (1991). Threatened Endemic Mammals of the Atlantic Forest Region of South-East Brazil. J. Jersey Wildl, Preservation Trust, Special Scientific Report.

Parker KA (2008). Translocations: providing outcomes for wildlife, resource managers, scientists, and the human community. Restor. Ecol. 16: 204-209.

Rohlf FJ (1992). NTSYS-pc Numerical Taxonomy and Multivariate Analysis System Vers. 1.70. Exeter Software, Setauket.

Roze U (2009). The North American Porcupine. 2nd edn. Cornell University Press, Ithaca.

Santos IB, Oliver WL and Rylands AB (1987). Distribution and status of two tree porcupines. Chaetomys subspinosus and Sphiggurus insidiousus in south-east Brazil. J. Jersey Wildl. 24: 43-60.

Vilela RV, Machado T, Ventura K, Fagundes V, et al. (2009). The taxonomic status of the endangered thin-spined porcupine, Chaetomys subspinosus (Olfers, 1818), based on molecular and karyologic data. BMC Evol. Biol. 9: 29.

Williams JG, Kubelik AR, Livak KJ, Rafalski JA, et al. (1990). DNA polymorphisms amplified by arbitrary primers are useful as genetic markers. Nucleic Acids Res. 18: 6531-6535. 